\title{
CARACTERÍSTICAS DAsS ÁÁREAS PROTEGIDAS EM GUINÉ-BISSAU: O CASO DO PARQUE NATURAL DOS TARRAFES DO RIO CACHEU
}

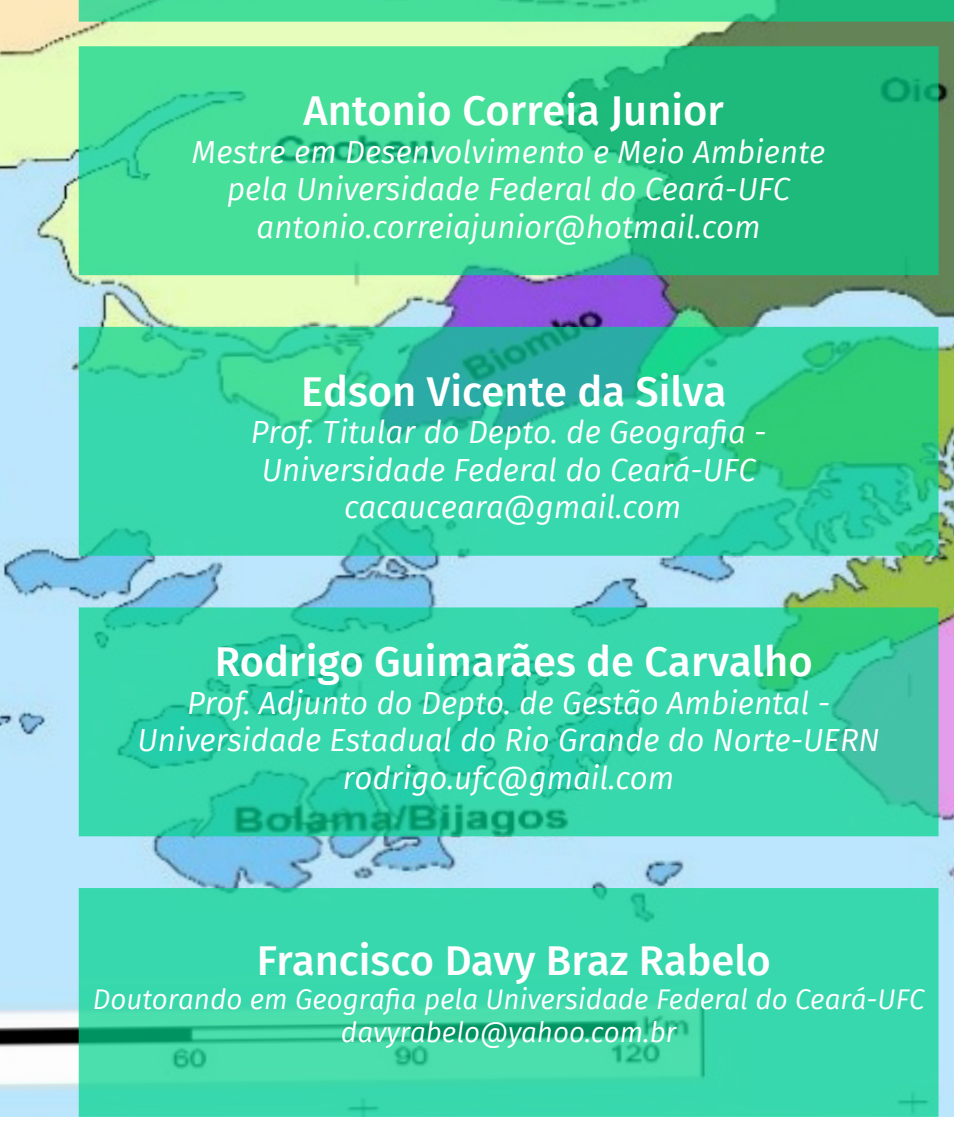

\section{RESUMO}

Atualmente se observa uma crescente degradação da biodiversidade em diferentes escalas de análise, interferindo na dinâmica ambiental global, regional e local, incluindo os sistemas ambientais das regiões litorâneas e costeiras da Guiné-Bissau, devido essencialmente à exploração abusiva dos recursos naturais e destruição dos ecossistemas. Cabe aqui instigar uma análise incorporando necessidades e cuidados no relacionamento sociedade-natureza diante a busca para satisfazer necessidades individuais humanas e sua ânsia de poder. Nesta ordem de ideias, faz-se necessário uma análise integrada dos sistemas ambientais, investigando a estratégia do governo nacional em busca de mecanismos para conservar o meio ambiente em Guiné-Bissau e as possiveis diretrizes que regem uma atuação de forma sustentável com a natureza, propondo a importância de um plano de manejo alternativo e sustentável dos recursos naturais. Nesse contexto, esta pesquisa objetiva, fornecer subsídios para a implementação e o desenvolvimento de ações direcionadas para a orientação da gestão dos recursos costeiros. Assim como,orientar o desenvolvimento dos planos relacionados ao planejamento e gerenciamento integrado do Parque Natural dos Tarrafes do rio Cacheu-PNTC. Pretende contribuir com propostas para mitigação das ações danosas na região de Cacheu e nos sistemas ecológicos locais, objetivando fornecer subsídios para a implementação e o desenvolvimento de ações direcionadas para a orientação da gestão dos recursos costeiros, sistematizar o desenvolvimento dos planos futuros de gerenciamento integrado do Parque Natural dos Tarrafes do rio Cacheu/Guiné-Bissau, de forma a subsidiar a efetivação de propostas de gestão ambiental do ecossis tema manguezal. Os procedimentos metodológicos da pesquisa fundamentaram-se em discussões e estudos teóricos de análise geossistêmica, através da coleta de dados secundários, revisão bibliográficae levantamentos de campo. Estas etapas permitiramcompreender a dinâmica das áreas que permaneceram coma vegetação natural e aquelas em que houve a exploração humana ao longo do tempo. Portanto este estudo levou ao conhecimento da efetivação de uma gestão ambiental ineficiente buscando reverter e/ou prevenir os impactos socioambientais decorrentes das transformações das paisagens naturais locais. Diante do exposto pode-se constatar que, a paisagem natural das áreas protegidas em Guiné-Bissau no caso do PNTC, apresenta-se como um ambiente fortemente modificado, onde a vegetação primária foi quase que totalmente substituída por sucessões ecológicas secundárias, em virtude da ação degradadorahumana. A área em estudo é apontada como um ecossistema submetido a impactos ambientais drásticos, sendo a vegetação seriamente ameaçada pelo uso inadequado do solo, havendo necessidade de promover estudos especializados, capazes de conduzir a um desenvolvimento sustentável.

Palavras - chave: Ecossistema Manguezal, Desenvolvimento Sustentável, Parque Natural dos Tarrafes.
Actualmente se observa una creciente degradación de la biodiversidad en diferentes escalas de análisis, interfiriendo en la dinámica ambiental global, regional y local, incluyendo los sistemas ambientales de las regiones costeras y costeras de Guinea-Bissau, debido esencialmente a la explotación abusiva de los recursos naturales y la destrucción de los ecosistemas. Cabe aquí instigar un análisis incorporando necesidades y cuidados en la relación sociedad-naturaleza ante la búsqueda para satisfacer necesidades individuales humanas y su afán de poder. En este orden de ideas, se hace necesario un análisis integrado de los sistemas ambientales, investigando la estrategia del gobierno nacional en busca de mecanismos para conservar el medio ambiente en Guinea-Bissau y las posibles directrices que rigen una actuación de forma sostenible con la naturaleza, proponiendo la importancia de un plan de manejo alternativo y sostenible de los recursos naturales. En este contexto, esta investigación objetiva, proporcionar subsidios para la implementación y el desarrollo de acciones dirigidas a la orientación de la gestión de los recursos costeros. Así como, orientar el desarrollo de los planes relacionados con la planificación y gestión integrada del Parque Natural de los Tarrafes del río Cacheu-PNTC. Se pretende contribuir con propuestas para mitigar las acciones dañinas en la región de Cacheu y en los sistemas ecológicos locales, con el objetivo de proporcionar subsidios para la implementación y el desarrollo de acciones dirigidas a la orientación de la gestión de los recursos costeros, sistematizar el desarrollo de los planes futuros de gestión integrada Parque Natural de los Tarrafes del río Cacheu/Guinea-Bissau, para subsidiar la efectividad de propuestas de gestión ambiental del ecosistema manglar. Los procedimientos metodológicos de la investigación se fundamentaron en discusiones y estudios teóricos de análisis geosistémico, a través de la recolección de datos secundarios, revisión bibliográfica y levantamientos de campo. Estas etapas permitieron comprender la dinámica de las áreas que permanecieron con la vegetación natural y aquellas en que hubo la exploración humana a lo largo del tiempo. Por lo tanto este estudio llevó al conocimiento de la efectividad de una gestión ambiental ineficiente buscando revertir y / o prevenir los impactos socioambientales resultantes de las transformaciones de los paisajes naturales locales. En el caso del PNTC, el paisaje natural de las áreas protegidas en Guinea-Bissau, se presenta como un ambiente fuertemente modificado, donde la vegetación primaria fue casi totalmente sustituida por sucesiones ecológicas secundarias, en virtud de la cual, acción degradadora humana. El área en estudio es apuntada como un ecosistema sometido a impactos ambientales drásticos, siendo la vegetación seriamente amenazada por el uso inadecuado del suelo, habiendo necesidad de promover estudios especializados, capaces de conducir a un desarrollo sostenible.

Palabras clave: Ecosistema Manguezal, Desarrollo Sostenible, Parque Natural de los Tarrafes. 


\section{INTRODUÇÃO}

Guiné-Bissau é um país com superficie territorial de $36.125 \mathrm{~km}^{2}$, situada na Costa Ocidental da África, fazendo fronteira com a República do Senegal, ao Norte, a República da Guiné-Conakry, ao Leste e Sul e a oeste é banhado pelo oceano Atlântico. Além do território continental, o país integra uma parte insular composta por cerca de 40 ilhas, que constituem o arquipélago dos Bijagós no Sul, está separado do continente pelos canais de Geba, Pedro Álvares, Bolama e Canhabaque, para além das ilhas de Jeta e Pexice ao Norte. Tem uma população de 1.558 .090 habitantes com um indice de desenvolvimento entre os mais baixos do mundo, com $2 / 3$ da população vivendo abaixo da linha de pobreza com uma expectativa média de vida de 52 anos (INEC, 2009).

Guiné-Bissau está dividido em três províncias, Norte, Sul e Leste e subdividido em oito regiões que são: Bafata, Biombo, Bolama, Cacheu, Gabú, Oio, Quinara e Tombali e um setor autônomo Bissau (capital do país), como mostra a Figura 01.
Após a independência de Guiné-Bissau em 1973, iniciou-se todo um processo de transformação socioeconômica, a filosofia a ser seguida fundamentava-se na transformação da vida das populações, buscando a satisfação das suas necessidades básicas. Por outro lado, objetivava-se combater o poder tradicional que era considerado prejudicial ao desenvolvimento sustentável. Para tal, instaurou-se toda uma estrutura administrativa a fim de se aniquilar o sistema tradicional, que oficialmente foi substituído pelos comitês de aldeias organizados em setor e seções (ARASSI, 1994).

A Guiné-Bissau é considerada como um dos países mais ricos em termos da biodiversidade ao nível da África Ocidental e com uma costa marinha beneficiária do fenômeno de ressurgência, carregando muitos nutrientes utilizáveis para alimentação das espécies pesqueiras (GUINÉ-BISSAU, 2011). Apesar desta grande diversidade e excepcionais condições ambientais, se nota que o meio ambiente local, tem sofrido grandes modificações, seguidas da degradação do seu potencial biológico, causadas por ações antropogênicas ou por práticas incompatíveis com os princípios de uma gestão durável dos recursos naturais, destacando-se o mau uso dos recursos naturais que leva a pobreza das populações rurais.

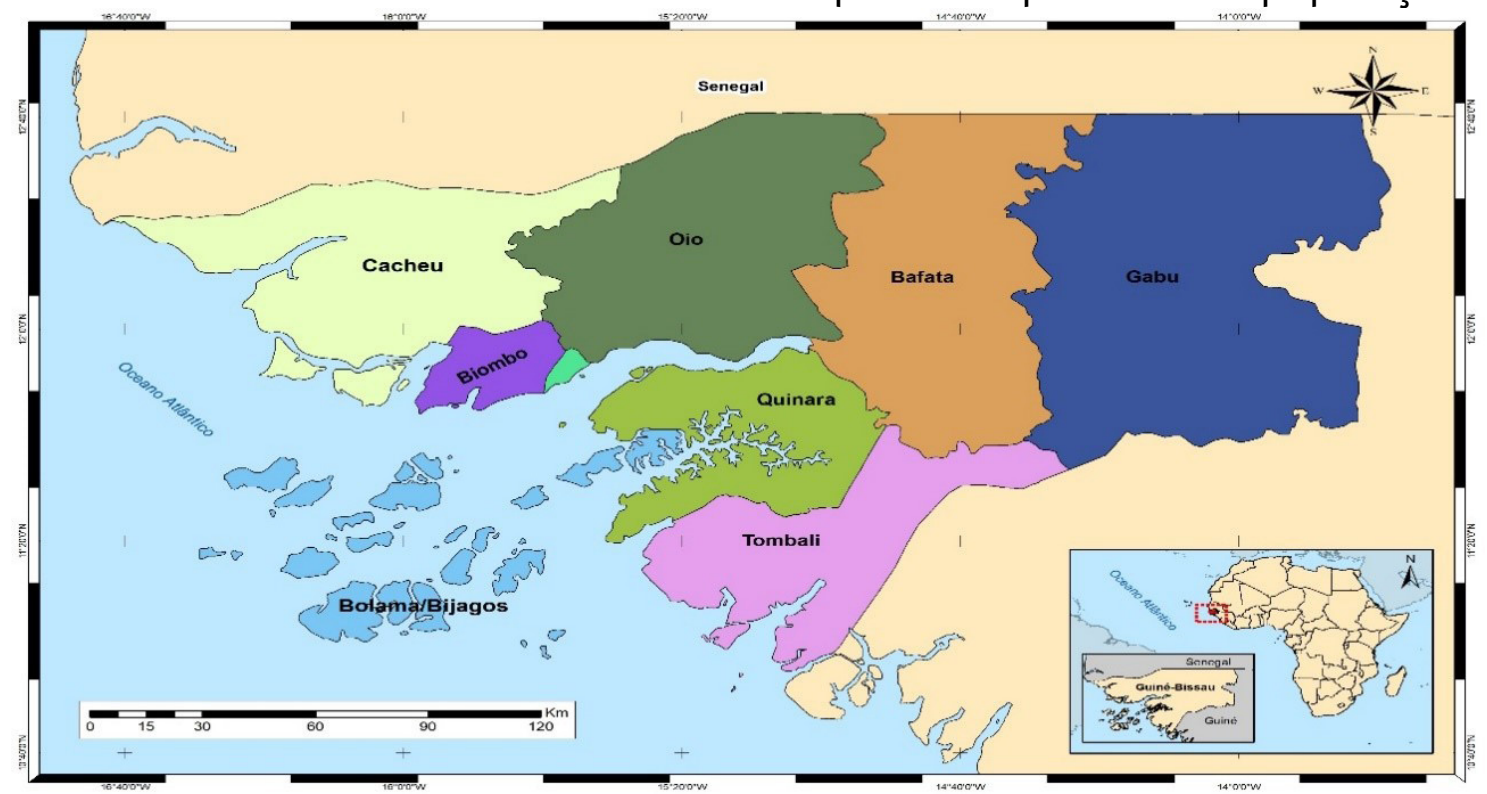

Figura 1. Mapa político e divisão administrativa da Guiné-Bissau. Elaboração: Autores (2018). 
No ano de 1989 foi iniciado o processo de discussão sobre a Estratégia Nacional de Conservação, apoiado pela União Internacional para Conservação da Natureza (UICN) e União Europeia, no qual, o seminário realizado no mesmo ano assinala como oportuna a planificação da gestão dos recursos naturais da zona costeira, a conservação dos manguezais e a criação de áreas protegidas como prioridades (IBAP, 2008).

Ainda em 1989, iniciou-se o Projeto da Planificação Costeira no quadro da Direção Geral das Florestas e Caça, com o apoio da UICN e da Agência da Cooperação Suíça, cuja proposta preliminar apresentada em 1990 foi objeto de uma discussão que decorreu cerca de um ano, a fim de tornar uma proposição real de criação de quatro parques nacionais, cujo funcionamento levava em consideração os sistemas tradicionais de gestão dos recursos naturais (IBAP, 2008).

Guiné-Bissau conta atualmente com um Sistema Nacional de Áreas Protegidas (SNAP), com seis áreas protegidas, abrangendo uma superficie de 470.000 ha, um terço dos quais corresponde a terras permanentemente emersas e os restantes dois terços são de manguezais, bancos intermareais e águas marinhas poucos profundos (menos de $10 \mathrm{~m}$ ). Quatro destas áreas protegidas têm um forte componente marinho e estuarina que são: Parque Nacionais de Orango e de João Vieira Poilão; Área Protegida Comunitária das Ilhas de Urok; Parque Natural dos Tarrafes do rio Cacheu, enquanto que o Parque Natural das Lagoa de Cufada e Parque Nacional de Cantanhéz, protegem lagoas e ecossistemas florestais locais (IBAP, 2008).

Esta pesquisa teve por objetivo compreender os aspectos gerais da criação e implantação de áreas protegidas em Guiné Bissau e, para isso, desenvolveu um estudo específico no Parque Natural dos Tarrafes do Rio Cacheu. Foram seus objetivos específicos: i) Compreender a estrutura, os valores e a lógica do Sistema Nacional de Áreas Protegidas;

ii) Identificar os problemas ambientais do Parque Natural dos Tarrafes do rio Cacheu (PNTC);

iii) Verificar a percepção da população residente no PNTC sobre a gestão da área protegida.

\section{REFERENCIAL TEÓRICO}

\section{O ECOSSISTEMA MANGUEZAL}

Os manguezais são ecossistemas predominantemente tropicais que cumprem funções ecológicas de significativa importância para a reprodução de espécies marinhas. Os nutrientes encontrados nos manguezais contribuem para a produtividade primária, alimentando grandes populações de moluscos, crustáceos, peixes, aves nativas e migratórias. Portanto, são berçários naturais, ou seja, ambientes para reprodução e criadouro de uma forma rica e diversa (SILVA, 1987 e THIERS; MEIRELES; SANTOS, 2016). Conforme os autores, os manguezais são ecossistemas muito importantes em vários aspectos: (1) biologicamente, por terem um alto nível de biodiversidade de fauna, já que mais de $90 \%$ dos seus peixes comercializáveis, além de outras espécies aquáticas, passam a maior parte de seu ciclo vital nos manguezais; (2) ecologicamente, por desempenharem um papel crucial na fertilização, estabilização, filtração, regulação do microclima e agirem como apoio da cadeia alimentar e como viveiros para muitas espécies de invertebrados e peixes; (3) economicamente, por providenciarem um amplo leque de produtos florestais madeireiros e não madeireiros que sustentam as economias rurais e têm alto potencial ecoturístico.

Na perspectiva ecológica, o manguezal é visto como "sistema costeiro tropical, dominado por espécies vegetais típicas, às quais 
se associam outros componentes da flora e da fauna, microscópicos e macroscópicos, adaptados a um substrato periodicamente inundado pelas marés, com grandes variações de salinidade" (SCHAEFFER-NOVELLI, 2002, p. 8).

Os manguezais têm uma importância estratégica para a sobrevivência de espécies, inclusive para o próprio ser humano. São ecossistemas conhecidos pela sua relevância, no que tange à produção de biomassa, por favorecerem a transformação de nutrientes em matéria orgânica e por ser um dos ecossistemas mais produtivos no mundo, funcionando como berçário natural para várias espécies de moluscos, crustáceos e peixes de interesse econômico (CARVALHO at al., 2007). Segundo o autor supracitado, os manguezais são ecossistemas característicos de regiões tropicais e subtropicais, e representam um ecossistema de grande importância ecológica, biológica, biogeográfica, geológica e humana, devendo ser abordado em várias perspectivas, mas sempre visando à sustentabilidade socioambiental.

Mesmo ciente da importância sociocultural e ecológica do ecossistema manguezal, as pressões antrópicas têm interferido negativamente em escala espacial e temporal de forma crescente, trazendo consigo consequências degradantes às diversas formas biológicas ali inseridas, inclusive as condições de vida humana. Nas regiões costeiras africanas, em especial, no litoral guineense, estes cenários não se diferem, pois percebe-se a ocorrência de diferentes processos de degradação ambiental. Segundo Ajonina et al. (2008), as causas subjacentes da degradação dos manguezais no continente africano, estão associadas com a pressão populacional, dificuldades de manejo adequado e o estado de pobreza das comunidades locais e a distribuição desigual dos recursos por parte de ações do Estado.

O manguezal é um sistema ecológico costeiro tropical limítrofe entre a terra e o mar, localizado em terrenos baixos na foz dos rios e estuários, com solos inundados pelas variações das marés e das águas fluviais, apresentando grandes variações de salinidade e marés (VANNUCCI, 2003). Ainda conforme o autor, o sistema manguezal é insubstituível e prospera onde nada mais cresce, consiste em um sistema altamente produtivo e funciona como suporte de vida, com intensa ciclagem de nutrientes, exportando-os para os sistemas vizinhos, contribuindo ainda para sustentar a pesca costeira estuarina. Alves; Nishida (2002, p.12), consideram que o manguezal é "uma unidade ecológica da qual depende grande parte da população humana, constituindo-se um ponto de partida para o sustento, tendo, assim uma grande importância econômica".

O ecossistema manguezal "possui grande importância para a manutenção e o sustento do equilíbrio ecológico da cadeia alimentar das regiões costeiras" (NASCIMENTO, 2007, p. 2). Constituium dos principais ecossistemas costeiros tropicais, sendo importantes transformadores de matéria orgânica. Para Lanna (2004), o manguezal apresenta condições propicias para a alimentação, proteção e reprodução de muitas espécies de animais aquáticos, tanto marinhos quanto estuarinos e até mesmo alguns dulcícolas, que necessitam dessas áreas para se reproduzirem durante o seu ciclo biológico e desenvolver diferentes fases larvais das suas respectivas proles.

A grande parcela da população do planeta depende dos ecossistemas manguezal e dos serviços que eles oferecem, incluindo alimentos, água, regulação climática, satisfação espiritual e apreciação estética. Diante dos fatos narrados por autores, constata-se que a flora dos estuários éconstituída por espécies essenciais para conservação da diversidade biológica, oferecendo proteção, viveiros, nutrientes para diferentes animais e entre outros beneficios ecológicos ao ambiente regional.

Uma grande diversidade de animais e outros organismos vivos dependem dos processos ecossistêmicos desses bosques costei- 
ros, sendo a função dos manguezais na cadeia alimentar marinha, uma condição vital para sobrevivência de muitas populações no mundo. Neste contexto, estima-se que $80 \%$ das capturas mundiais de peixes em zonas costeiras tropicais são dependentes dos manguezais e dos sistemas de recifes coralinos (FIELD, 1998; FAO, 2007; ELLISON, 2008; apud QUEIROZ et al., 2012).

As maiores extensões de cobertura de manguezais em Guiné-Bissau encontram-se, especificamente nos rios Buba e Geba (localizados na Província Sul) e no rio de Cacheu, (presente na Província Norte) (Figura 02).0 delta do rio Cacheu tem a maior diversidade de cobertura de mangue na costa Ocidental da África, alberga cerca de $60 \%$ dos manguezais da Guiné-Bissau e estende-se por uma exten-
Conocarpus erectus; e Rhizophora harrisonii, R. mangle, R. racemosa - geralmente chamados de mangues vermelhos. A R. racemosa é a espécie dominante na região e tem como características varas longas e retas em grupos puros especialmente nos estuários de maré. A R. manglesão árvores pequenas e arbustos respectivamente (SPALDING et al., 1999). Para além dessas regiões sul e norte do país existem outras áreas de ocorrência de manguezais, inclusive no setor leste.

Os manguezais do rio Cacheu, Corubal e Geba desempenham um papel fundamental na subsistência de mais de 128.000 pessoas que vivem na região. Ademais, elas são importantes para a economia do país, contribuindo desse modo para o setor da pesca.

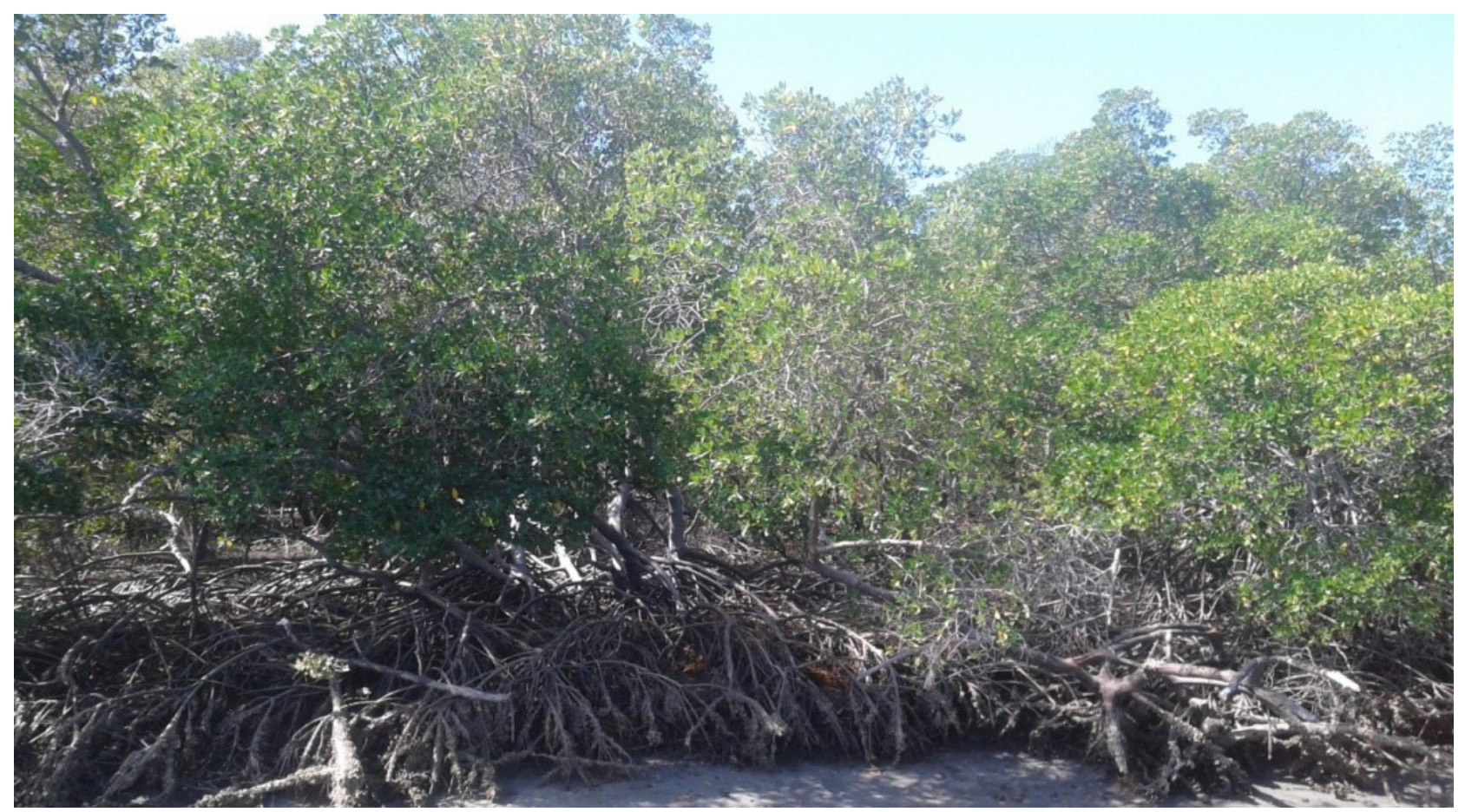

Figura 2. Planície estuarina do rio Cacheu, Guiné-Bissau.

Fonte: Autores, 2018.

são de $550 \mathrm{~km}$ ao longo da costa e 350 para o interior do país. Entre as espécies encontradas nesse manguezal, destacam: Avicennia germinans - conhecida como mangue-branco; Laguncularia racemosa (mangue-branco). 


\section{POLÍTICAS PÚBLICAS DE PROTEÇÃO DOS MANGUEZAIS EM GUINÉ-BISSAU}

Destaca-se que o desafio de conservar os manguezais deve ser assumido por todos os países, pois, mesmo os que não possuem manguezais, devem se comprometer com a manutenção da biodiversidade global, sendo essa uma questão ética e que impõe necessariamente restrições ao desenvolvimento das atividades produtivas, a exploração do solo, a construção de infraestrutura e ao regime de uso da propriedade privada e pública (GANEM, et al., 2010).

Em Guiné-Bissau quase não existempolíticas públicas para proteção do manguezal, o que existe é a leiflorestal que engloba tudo, afirmando que a floresta, no conjunto de todos os seus recursos é um patrimônio nacional suporte de um projeto de desenvolvimento que visa atingir a segurança alimentar e o bem estar do povo e nessa base deve ser considerada e protegida, sem perder de vista, porém a política traduzida na ideia de desengajamento progressivo da intervenção do Estado na vida econômica nacional. Assim, as florestas, os sistemas naturais ou artificiais cujas formações vegetais são classificadas como manguezal, palmar, floresta de galeria, florestas, sub-umidas, densas, semi-seca clara, subtropical, em regeneração e ainda savana arborizada e savana herbácea, são consideradas como protegidas.

Neste caso compete designadamente e estritamente obediência hierárquica ao ministro tutelar a Direção Geral das Florestas e Fauna (DRFF), a coordenar e fiscalizar a execução da política florestal, proteção, conservação e da gestão racional dos recursos florestais. A classificação de florestas, onde se inclui o manguezal pode ser influenciada também pela cobertura e densidade da vegetação, esta problemática é dificultada desde a fase de recolha de informação no terreno, pois a própria semântica da definição de formações florestais enquanto tal é matéria de grande debate (SEXTON et al., 2015).

A proposta de Lei dos manguezais atualmente em discussão é a resposta efetiva à medida da Estratégia Nacional para as Áreas Protegidas e a Conservação da Biodiversidade na Guiné-Bissau (IBAP 2014) e poderá melhorar as lacunas da Lei das Florestas, ao estabelecer a proteção e valorização dos manguezais. A elaboração de legislação de proteção dos manguezais na Guiné-Bissauprocura valorizar este ecossistema nas suas diversas valências.

\section{O PLANEJAMENTO E A GESTÃO AMBIENTAL EM ÁREA PROTEGIDAS}

De acordo com Santos (2004), o planejamento ambiental é compreendido como um processo através do qual se visa integrar informações, diagnosticar ambientes, prever ações e normatizar seu uso através de uma linha ética de desenvolvimento. Isso significa que para alcançar o desenvolvimento sustentável, o planejamento ambiental se faz necessário, pois analisa sistematicamente as potencialidades e riscos inerentes a utilização dos recursos naturais para o desenvolvimento da sociedade.

A crescente preocupação pela extração, exploração e pelo consumo dos recursos naturais de forma massiva, pelas variadas formas de poluição e pelos impactos socioambientais, verificados nas últimas décadas, desencadearam o surgimento de movimentos em defesa da conservação e preservação do meio ambiente (PACHECO, 2014). Na mesma direção de análise adotada por Pacheco (2014), se consideraram os estudos desenvolvidos por Quintas (2004), em que o autor afirma que o planejamento ambiental surge como resposta a esses movimentos, na tomada de decisões relativas à forma e à intensidade com que se deve usar, incluindo os assentamentos humanos, as organizações sociais e produtivas de coletas de informações, de análise e de 
reflexão sobre as potencialidades e limitações dos sistemas ambientais de um território.

Santos (2004), assegura que o planejamento ambiental surgiu na tentativa de responder ao aumento dramático da competição por terras, água, recursos energéticos e biológicos, que gerou a necessidade de organizar o uso da terra, de compatibilizar esse uso com a proteção de ambientes ameaçados e de melhorar a qualidade de vida das populações. Para Seiffert (2014, p. 45), “o processo de gestão ambiental surge como alternativa para buscar a sustentabilidade dos ecossistemas antrópicos, harmonizando suas interações com os ecossistemas naturais". Contudo, para obter essa harmonização, através da gestão ambiental, é necessário lidar com situações extremamente complexas, envolvendo uma realidade problemática cujas condições necessitam ser melhoradas. Isso implica, na maioria das vezes, lidar com interventores ou agentes que apresentam interesses conflitantes em relação à forma de utilização de um determinado bem ambiental.

A importância do planejamento ambiental deve-se ao seu funcionamento, enquanto uma ação preventiva contra os possiveis problemas ambientais decorrentes do desordenamento predominante da ocupação territorial. Nesse sentido, a ocupação planejada tem a função de beneficiar a população através de medidas preventivas e mitigadoras dos problemas ambientais.

Para Rodriguez; Silva; Cavalcanti (2007) o planejamento ambiental do território converte-se em "um elemento tanto básico como complementar para a elaboração dos programas de desenvolvimento econômico e social, e para a otimização do plano de uso, manejo e gestão de qualquer unidade territorial" (RODRIGUEZ; SILVA; CAVALCANTI, 2007, p. 57). Segundo Silva et al., (2014), os processos de planejamento ambiental devem ser participativos, e é preciso ouvir com zelo a experiência das comunidades científicas e tradicionais, assim como devem ser realizadas interven- ções sensibilizadoras sobre as limitações e potencialidades do uso da paisagem. Os referidos autores afirmam que, as ações de planejamento e de gestão ambiental de qualquer paisagem devem considerar um conhecimento prévio sobre as relações existentes entre a sociedade e a natureza, que viabilizam resoluções de conflitos ambientais e, consequentemente, permitem que a gestão alcance resultados benéficos.

Para Philippi Jr. (2004) e Seiffert (2014), a gestão ambiental na esfera pública é dependente da implementação pelo governo de sua política ambiental, mediante a definição de estratégias, ações, investimentos e providências institucionais e jurídicas, com a finalidade de garantir a qualidade do meio ambiente, a conservação da biodiversidade e o desenvolvimento sustentável. A gestão ambiental deve contribuir com a efetivação de práticas que garantam a conservação e preservação da biodiversidade, a reciclagem das matérias- primas e a redução dos impactos ambientais das atividades humanas sobre os recursos naturais.

\section{MATERIAL E MÉTODOS}

\section{PESQUISA BIBLIOGRÁFICA E DOCUMENTAL}

A revisão bibliográfica e documental consistiu na leitura de diversos livros, teses dissertações, leis, políticas, artigos disponibilizados nas bibliotecas da Universidade Federal de Ceará (UFC) e da Universidade Estadual do Ceará (UECE), Instituto Federal de Ciência e Tecnologia do Ceará (IFCE), nos Laboratórios do Departamento de Geografia da Universidade Federal do Ceará (UFC), Laboratório de Estudos Agrários e Territoriais (LEAT), Laboratório de Planejamento e Gestão Ambiental (LAGEPLAN) entre outros documentos oficiais e editais que tratam sobre os assuntos relacionados ao tema em discussão, bem como ao 
território da Guiné-Bissau.

Objetivando compreender abordagem do tema em estudos desenvolvidos em Guiné-Bissau recorreu-se em algumas instituições de ensino superior público e privado como Universidade Lusófona de Amílcar Cabral (UAC); Faculdade de Direito da Guiné-Bissau (FDGB), Biblioteca Regional de Cacheu (BRC), Memorial da Escravatura e do Tráfico de Cacheu Negreiro (METNC), Instituto Nacional de Estudos e Pesquisa da Guiné-Bissau (INEP), Instituto da Biodiversidade e das Áreas Protegidas da Guiné-Bissau (IBAP) e União Internacional para a Conservação da Natureza (UICN).

Esta fase permitiu a obtenção das bases teóricas e das linhas ligadas ao tema e também a construção de mecanismos para a coleta de dados no campo e contribuiu para o estabelecimento de limites internos e externos, ligados aos conceitos dos temas estudados. A pesquisa no âmbito da internet, também de igual modo, apoiou esta fase na busca de informações relacionadas com as temáticas do estudo. Durante esta etapa, foram analisadas figuras, fotos, quadros, contido nas informações bibliográficas e documentais pesquisadas ou que estiveram essencialmente ligadas aos inventários dos aspectos ambientais.

\section{PESQUISA DE CAMPO NO PARQUE NATURAL DOS TARRAFES DO RIO CACHEU}

No PNTC, foram aplicados 25 entrevistas estruturadas com líderes comunitários locais, segundo determina as leis dos anciões e a cultura local, que a palavra final é dada pelo líder comunitário, que passou conhecimentos das reais situações ou problemas enfrentados pela comunidade, por se tratar de um representante influente na comunidade que tem a função de determinar as áreas destinadas à preservação e à conservação dos ecossistemas locais vinculados com a segurança alimentar das comunidades tradicionais. Salien- ta-se que os questionários foram aplicados com pessoas de ambos os sexos, entre as idades compreendidas de 18 a 70 anos.

Após o trabalho de coleta de dados no campo, as informações foram organizadas e tratadas com o uso do software Microsoft Office (Word e Excel), Gráficos e o Picture Maneger. Foram elaborados resumos dos dados em quadros, tabelase gráficos, relacionados com os aspectos ambientais inventariados na área de estudo. Os registros obtidos por meio de fotografias e entrevistas foram selecionados detalhadamente para constarem do texto escrito de acordo com os objetivos estabelecidos para o trabalho.

\section{RESULTADOS E DISCUSSÃO}

\section{AS ÁREAS PROTEGIDAS EM GUINÉ- BISSAU}

O Governo da Guiné-Bissau instituiu legalmente várias zonas de conservação dentro do território nacional, conhecidas como Rede Nacional de Áreas Protegidas (RNAP) com uma cobertura de $12,2 \%$ do território nacional. Assim o Governo da Guiné-Bissau decreta nos termos de artigo 100 no 1 alínea d, da Constituição de 2011, o seguinte:

Toda e qualquer parcela do território nacional classificada como uma área protegida visa designadamente salvaguardar os seus ecossistemas, as populações animais e vegetais, que nela abrigam a sua diversidade biológica bem como promover o seu desenvolvimento durável.

A área protegida tem por objetivo, salvaguardar as espécies animais, vegetais e os habitats ameaçados; salvaguardar os biótipos e formações naturais e os sítios de interesse cultural; conservação e recuperação de habitat da fauna migratória e dos seus corredores; 
promoção de investigação e pesquisa científica e das ações de educação ambiental; defesa, conservação e valorização das atividades e formas da vida tradicionais não lesivas ao patrimônio ecológico; proteção e valorização das paisagens únicas, raras ou típicas, cujo valor cênico thes confira interesse especial; promoção e apoio ao desenvolvimento utilização durável dos recursos naturais visando o desenvolvimento econômico e bem-estar das comunidades.

As áreas protegidas podem ser do tipo: a) Parque Nacional; (b) Reserva Natural Integral; (c) Zona de Natureza de Selvagem; (d) Monumento Natural; (e) Área Administrada para Habitat e Espécies; (f) Paisagem Terrestre ou Marinha Protegida; (g) Área Protegida de Recursos Naturais Administrados; (h) Área Protegida Comunitária e (i) Florestas e Sítios Sagrados (GUINÉ-BISSAU, 2011).

a) Parque Nacionalé designado no sentido de proteger a integridade ecológica de um ou vários ecossistemas, para o bem das gerações presentes e futuras; excluir toda a exploração ou ocupação incompativel e dar a possibilidade de visita com finalidades científicas, educativas, espirituais, recreativas ou turísticas, mas com respeito ao meio natural e a cultura das comunidades locais;

b) Reserva Natural Integral é um espaço terrestre ou marinho, integrando os ecossistemas, os elementos geológicos, físico ou ainda que possui espécies disponiveis para a investigação cientifica ou monitoramento ambiental;

c) Zona de Natureza Selvagemconstitui um vasto espaço terrestre ou marinho, intacto ou pouco modificado pelas ações antropogênicas, com o objetivo de preservar e conservar o seu caráter natural;

d) Monumento Natural corresponde uma área contendo um ou vários elementos naturais e culturais particulares de importância singular, a ser protegida pela sua raridade, representatividade e suas qualidades estéti- cas ou de importância cultural intrínseca;

e) Área Administrada para Habitat e Espécies, corresponde a uma área terrestre ou marinha com vista a uma intervenção ativa em matéria de gestão, de modo a garantir a manutenção dos habitats ou satisfazer as exigências de espécies particulares;

f) Paisagem Terrestre ou Marinha Protegida afigura-se como uma zona terrestre englobando por vezes a costa e o mar, cuja paisagem se reveste de qualidades ecológicas ou culturais particulares resultando de interação antiga do homem e da natureza e a preservando muitas vezes, com uma grande diversidade biológica. A manutenção da integridade desta interação tradicional é essencial para a proteção, a manutenção e a conversação da área;

g) Área Protegida de Recursos $\mathrm{Na}$ turais Administrados contém sistemas naturais, em grande parte não modificados, são gerenciados de forma a assegurar a proteção e a manutenção ao longo prazo da diversidade biológica, tendo em vista garantir a durabilidade das funções e dos produtos naturais necessários ao bem-estar das comunidades;

h) Área Protegida Comunitária constitui uma área que visa promover a gestão dos espaços e dos recursos, assenta-se na recuperação e atualização das regras tradicionais e científicas de gestão de recursos naturais;

i)Florestas ou Sítios Sagrados são espaços naturais destinados exclusivamente a manifestações tradicionais de cunho cultural e religioso onde a gestão dos recursos naturais é determinada pelos usos costumes da comunidade que os utilizam.

Segundo IBAP (2013), a preocupação com a natureza e a sua conservação sempre esteve presente em Guiné-Bissau, os antepassados protegiam a natureza através da consagração tradicional dos sítios, que entendiam serem importantes. Alguns sítios sagrados ainda existem até hoje (floresta, rio, fonte, mangue- 
zais), e continuam a guardar as suas características naturais e especiais, graças a esta forma tradicional de conservação.

Nos últimos anos tem se verificado a propagação de práticas nefastas sobre os recursos naturais locais, o que tem proporcionado um aumento da pobreza, a degradação do meio ambiente e a redução da biodiversidade em Guiné-Bissau. Cabe salientar que o crescimento populacional em Guiné-Bissau e o próprio desenvolvimento das sociedades, também são apontados como os grandes responsáveis pela crescente pressão atual existente sobre os recursos naturais.

A Guiné Bissau tem poucas indústrias ou aquelas que existem dispõem de pouca capacidade ao nível da prestação dos serviços essenciais para a satisfação das necessidades da população. Por isso, é da biodiversidade que provem grande parte dos serviços muito importantes para suprir as necessidades populacionais (IBAP, 2013).

Apesar dos avanços notáveis na criação de Áreas Protegidas em Guiné-Bissau, ainda há muitos desafios para garantir sua consolidação e a proteção socioambiental efetiva. Nestas áreas protegidas, quase $70 \%$ não possuem plano de manejo, além disso, o número de funcionários públicos inseridos nessas áreas protegidas é muito reduzido.

Os sistemas de zoneamento da maioria das Áreas Protegidas (AP), em Guiné-Bissau, são confusos, sobretudo nos limites dos parques no terreno, tanto em terra firme, como nos manguezais e no mar, o que dificulta ao respeito aos limites e acabam cometendo a exploração indevida nestas áreas. É necessário usar os planos de gestão das AP, sendo recomendávelredefinir os zoneamentos, aindaqueprovisoriamente, criando regras que permitam implementarum zoneamento participativo, com suas devidas categorias e com limites facilmente identificáveis.

\section{ÁREAS PROTEGIDAS: ESTUDO DO PARQUE NATURAL DOS TARRAFES DO RIO CACHEU}

O município de Cacheu está entre os seis territórios escolhidos para criação de parques, localmente recebeu nome "Parque Natural dos Tarrafes do Rio Cacheu", devido aos seus riquíssimos ecossistemas, que visa à conservação de manguezais, matas de palmeiras e uma elevada biodiversidade. O objetivo principal da criação da Área Protegida do Parque citado está voltado a manutenção da produtividade dos recursos naturais e a proteção da costa contra os processos de erosão. Em dezembro de 2000, criou-se o Parque Natural dos Tarrafes do rio Cacheu, através do Conselho dos Ministros da Guiné-Bissau (CMGB), pelas leis no 11,12 , e 13/2000 e publicados no Boletim Oficial no 49 de 04 de dezembro de 2000.

A área protegida do Parque Natural dos Tarrafes do rio Cacheu (PNTC) é composta essencialmente por dois setores: Setor Sul, localizado ao sul do rio Cacheu e Setor Norte, localizado ao norte do mesmo município. Salienta-se que dentro do PNTC existem mais de 50 tabancas (pequenos vilarejos), como pode-se ver na Figura 03.

A maioria das atividades de gestão deste parque concentra-se na parte sul e que apresenta uma área bem conservada de manguezal, a razão de uma relação harmônica de extrativismo da população deste setor, reflete no viver bem e na melhor conservação dos ecossistemas de manguezais, enquanto que a população do setor norte, são essencialmente agricultores da zona baixa e pescadores, causando assim maiores impactos nos ecossistemas de manguezais.

o Setor Norte, que tem uma grande área de manguezais, fica situado numa zona importante para a conservação. Destaca-se que os seus manguezais, são utilizados por um número elevado de aldeias fora dos limites 
do PNTC, cujos habitantes são de diferentes etnias, inclusive estrangeiras, com os seus hábitos e costumes bem como as formas de exploração diferentes, o que gera um risco para a sustentabilidade ambiental.

A superficie total do PNTC, incluindo os espaços aquáticos, apresenta uma área total de 94.824 ha, considerado o quinto maior parque com área contínua do ecossistema de manguezais na África Ocidental. Destes,19\% são propostos como núcleos de preservação,com objetivo de proteger e promover o uso sustentável dos recursos naturais (IBAP, 2008). (Figura 03).

Segundo Biai (2000), na área do PNTC,há uma superficie aproximada de cerca de 50.000 ha de manguezais, estima-se segundo o autor, que o mangue tenha diminuído a sua área de cobertura em $29 \%$ nos últimos 40 anos.

Atualmente a exploração dos manguezais se intensificou muito na região devido ao corte de árvores para obtenção de lenha para defumação do pescado, para construções de casas, assim como vedação de casas, há exploração de combés (moluscos bivalves), ostras, produção de sal, assim como a pesca. Essas práticas quando não controlado poderão provocar a erosão nas terras baixas e,consequentemente, causar efeitos secundários tais como alterações climáticas e assoreamento.

A maioria dos recursos referidos distribui-se de forma ampla por todo o PNTC, no que diz respeito aos recursos marinhos, no entanto, há uma clara concentração das atividades extrativas na zona sul.

Há indícios que a degradação está a acelerar-se rapidamente, o fator principal da ameaçade degradação dos manguezais nomunicípio de Cacheu são os desmatamentos para fins agricultura, nas áreas alagadas dos estuários.

\section{PROBLEMAS AMBIENTAIS NO PARQUE NATURAL DOS TARRAFES DO RIO CACHEU}

Os principais problemas ambientais identificados na região, sobretudo na área de proteção ambiental, junto às comunidades residentes no parque, destacados pelos técnicos, membros de conselho de gestão, são os seguintes: i) exploração de florestas; ii) exploração de Palmeiras; iii) exploração de Cibes; iv); exploração de manguezais; v) cortes de arvores e vi) agricultura itinerante.

i) Exploração de florestas: realizam-se queimadas que são feitas com objetivo de abrir as zonas de vegetação mais densas e facilitar a caça. De acordo com o resultado da pesquisa, são práticas que acontecem com muita frequência, ateiam o fogo intencionalmenteou, também, as vezes os incêndios acontecem acidentalmente. Essas práticas são detectadas todos os anos, com um grande número de ocorrência de queimadas de florestas.

ii) Exploração das Palmeiras: a prática é efetivada para extração do óleo de dendê, e da seiva, que irá caracterizar o chamado "vinho palma", utilizado para consumo, extração de candjirba (o resto de produção de óleo dendê). O óleo além de ser utilizado como combustivel para a iluminação, também é utilizada na alimentação havendo ainda a retirada da palha para a confecção de vassouras. Essas práticas são realizadas na área do Parque Natural dos Tarrafes do rio Cacheu, e no seu entorno, no município de Cacheu. A extração de vinho palma, muitas vezes origina a morte da própria palmeira, porque alguns exploradores que utilizam pregos e alguns utensílios que são fixados no meio da palmeira ouna parte superior da palmeira, para poder impulsioná- lo a uma maior saída das seivas (vinho palma). As Figuras 04 e 05, ilustram as práticas de exploração de palmeiras de dendê. 


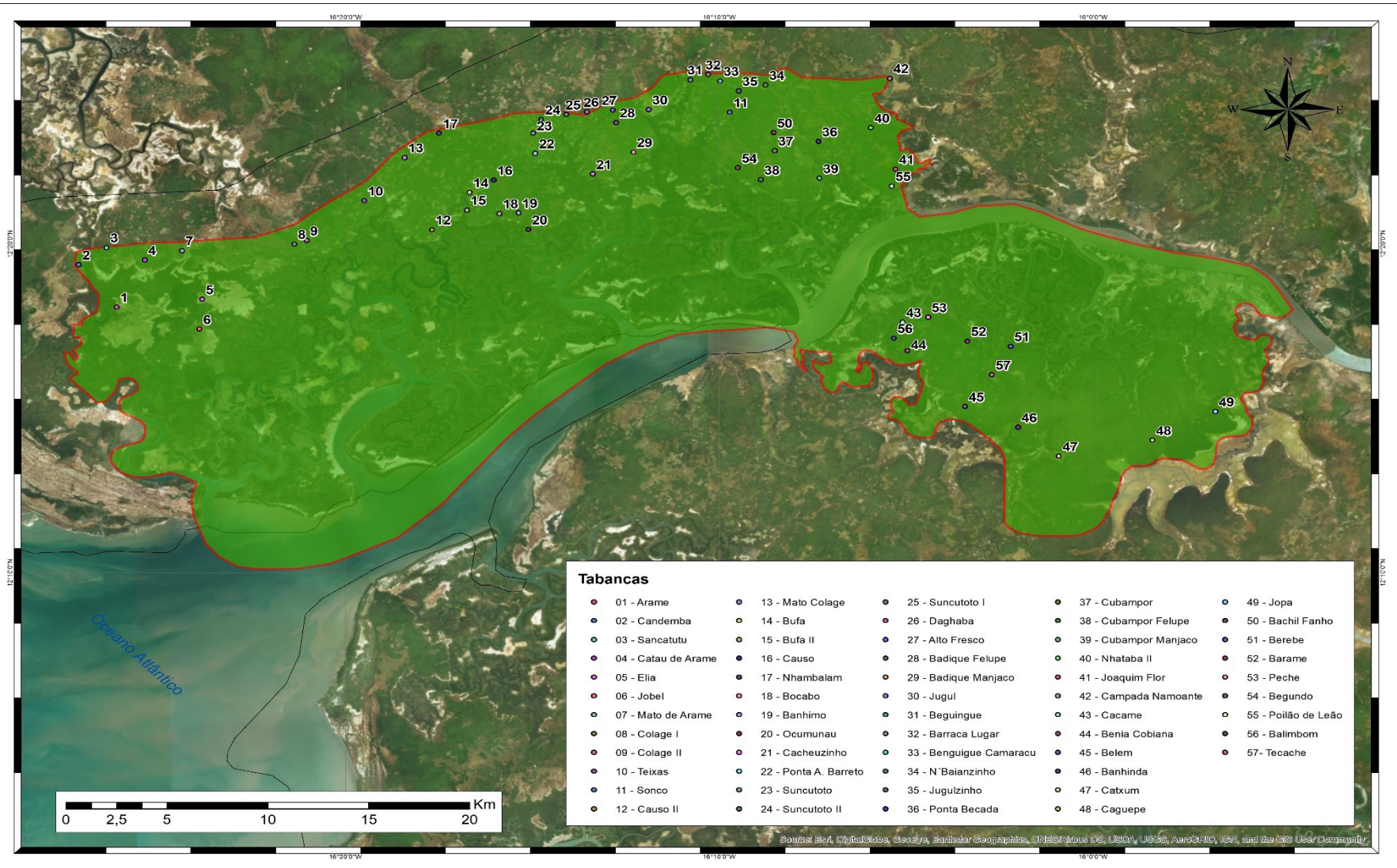

Figura 3. Mapa de localização do Parque Natural dos Tarrafes do rio Cacheu. Elaboração: Autores, 2018.

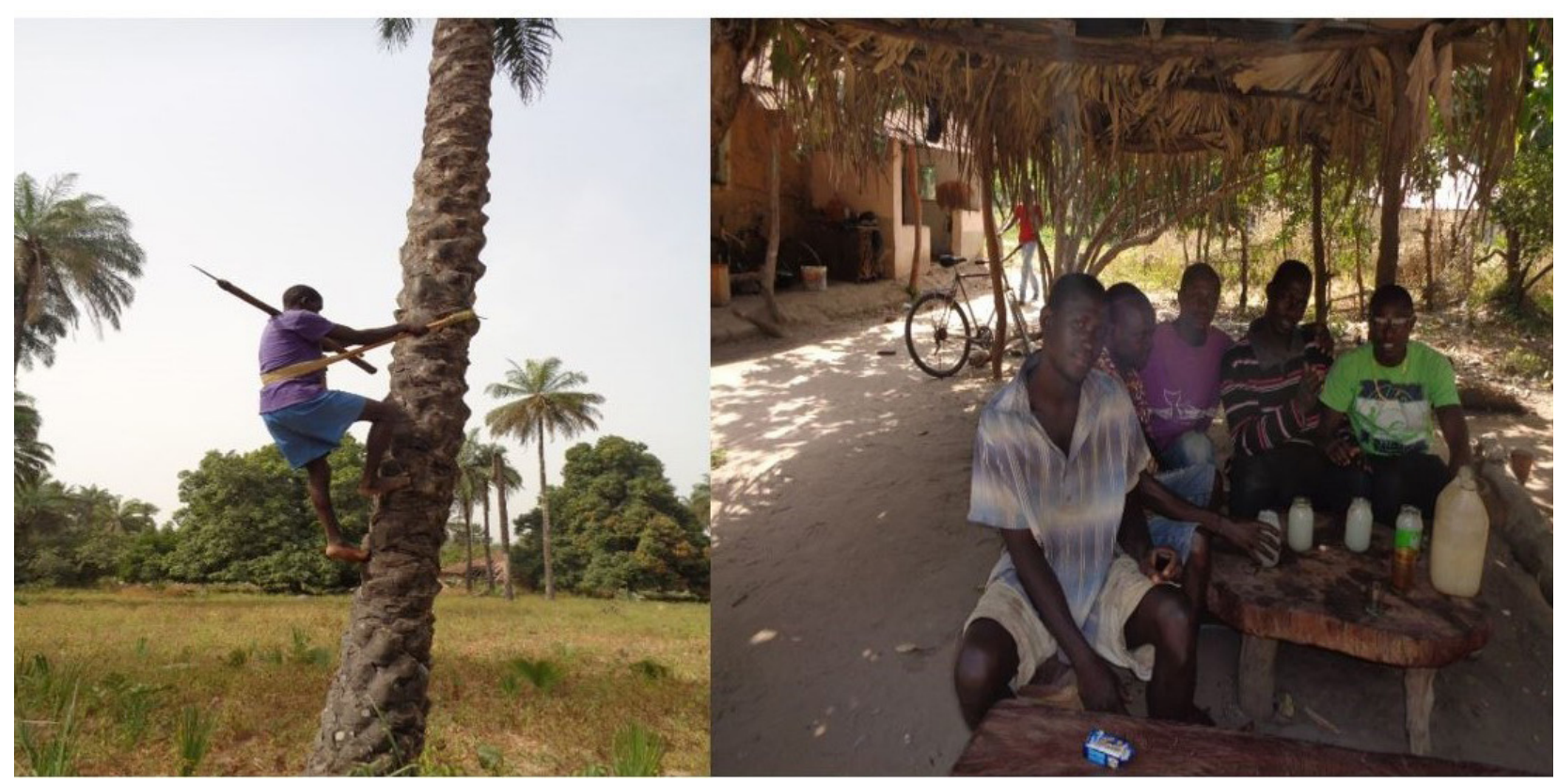

Figura 4. Mosaico de fotografias representando a extração e consumo da seiva de vinho palmo Foto: Autores, 2018. 


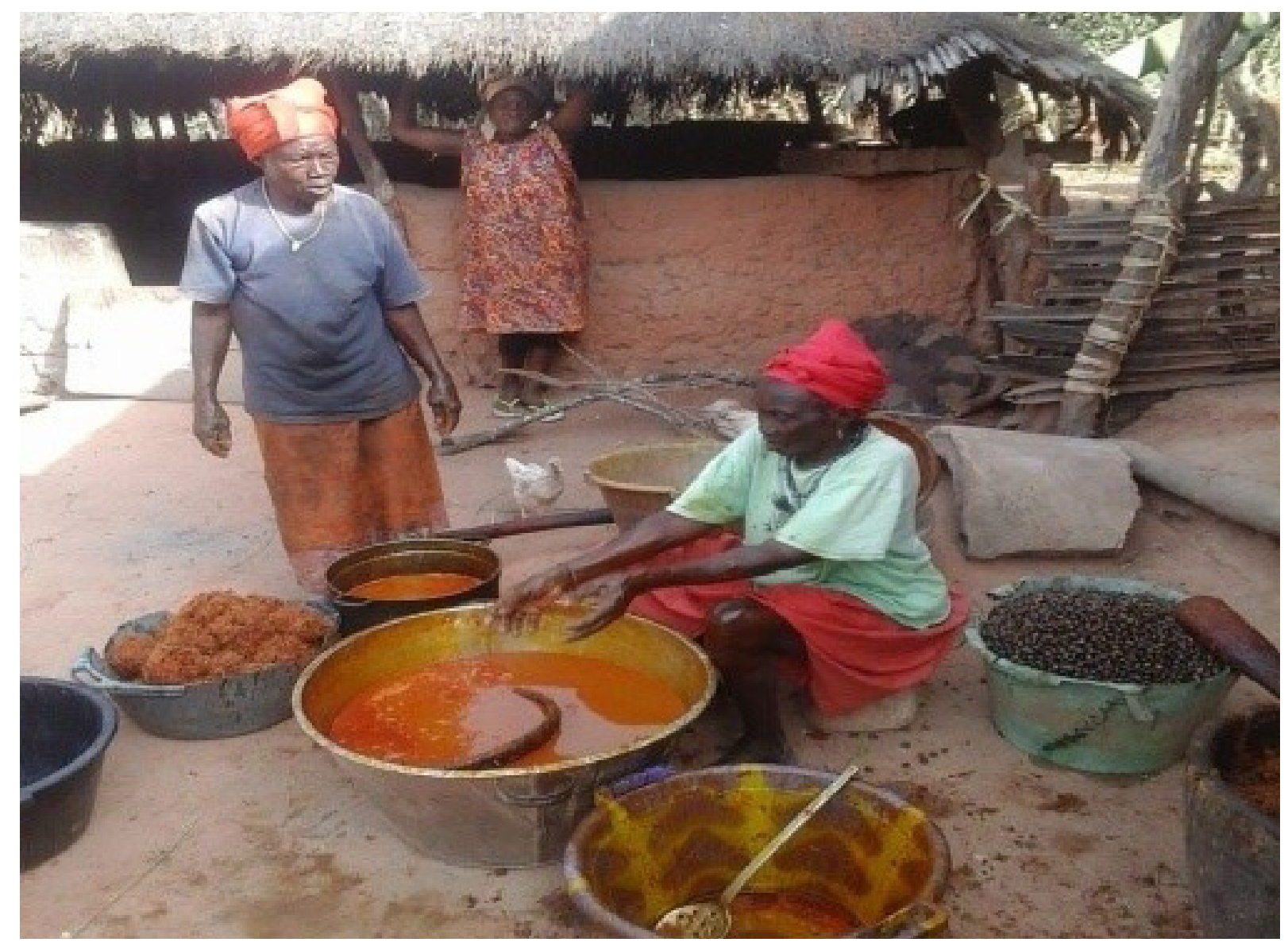

Figura 5. Fabricação do óleo de Dendê nas comunidades tradicionais Foto: Autores, 2018.

iii) Cortes de cibes: retirada de madeiras para construção de casas, cercos e instrumentos de pesca.

iv) Exploração de manguezais: ocasionado para obtenção de lenha para fumagem do pescado, vedação de casas, assim como abertura de campos para agricultura, retirada de madeira para fora do parque com finalidades de comercialização.

v) Cortes de arvores: para exportar madeiras, construção naval tradicionalmente, fabricação de pequenas embarcações canoas (pirogas), utilizadas na região principalmente na área que faz parte do parque. Todas essas embarcações são fabricadas nas comunidades locais a partir do corte de grandes árvores.

vi) Agricultura itinerante: grande parte de arroz consumido anualmente no município de Cacheu provém de lalas (áreas alagadas) ou arroz de sequeiro (pampam), para esse tipo de cultivo o agricultor precisa desmatar e queimar a vegetação original. Essas práticas destroem as zonas onde as matas são mais densas e desenvolvidas levando-as a uma degradação progressiva. Após sucessivas colheitas de arroz, atualmente começam-se a fazer plantação de caju, impedindo a regeneração natural das vegetações (Figura 06).

Essas práticas constituem uma das principais ameaças ambientais que contribuem para a degradação progressiva da cobertura vegetal no município de Cacheu, em particular nas zonas de preservação e de conservação do Parque Natural, transformando essas áreas de características florestais em savanas e levando a um empobrecimento do solo e a perda da diversidade faunística e florística. 

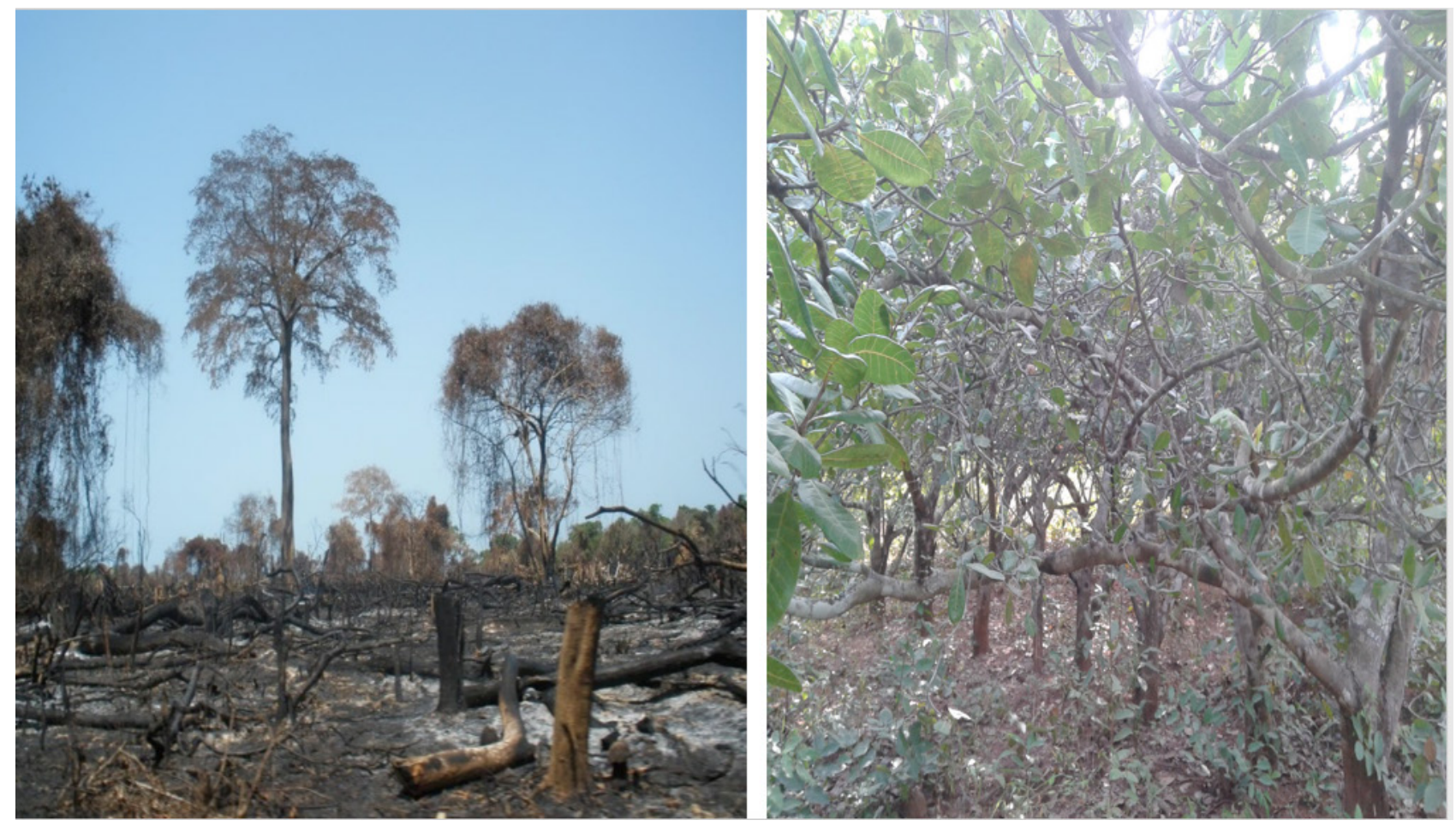

Figura 6. Agricultura itinerante e o sucessivo cultivo de cajueiros.

Foto: Autores, 2018.

\section{PERCEPÇÃO DOS MORADORES DO PNTC SOBRE A GESTÃO AMBIENTAL}

No questionário aplicado, encontram-se alguns padrões de respostas. Na primeira questão, em que se indagava: "Quanto ao planejamento ambiental, você acha que as autoridades têm envolvido, de forma eficiente, as comunidades locais na sua gestão"? Dentre os inqueridos, $92 \%$ informaram que não e apenas $8 \%$ disseram sim.

De acordo com a pesquisa, não há envolvimento das autoridades locais em questão ao planejamento e gestão ambiental, somente há uma objeção em relação à fiscalização do IBAP através do órgão ambiental nacional.

A população afirma que somente afiscalização não é suficiente. É importante ressaltar que seria necessária a sensibilização e a implantação de centros municipais, setoriais e comunitários com mediadores entre o poderpúblico e moradores, na efetivação das propostas de planejamento ambiental (Figura 07).

Perguntados “Em que medida está satisfeito ou insatisfeito com o trabalho realizado pelas autoridades na promoção da gestão ambiental"? Amaioria deles, $68 \%$ afirmaram muito insatisfeito, ver Figura 08.

Através do gráfico é evidente a afirmaçãode que a população do município de Cacheu está insatisfeita com o trabalho realizado pelas autoridades na promoção da gestão ambiental.

Foram questionados "De quem acha que é a responsabilidade da promoção e manutenção da qualidade ambiental" (enumere por grau de importância)? A questão teve por objetivo constatar a quem os moradores do município de Cacheu atribuem a responsabilidade da promoção e manutenção da qualidade ambiental dessa área. Para $68 \%$ questionados a incumbência da gestão e conservação é do Ministério de Meio Ambiente, $12 \%$ acham que o dever é de cada morador (individualmente), $8 \%$ atribuem a sociedade civil como responsáveis, $8 \%$ atribuem a associação comunitária, 
$3 \%$ responsabilizam ONGs e $1 \%$ responsabilizam secretaria de meio ambiente. A resposta mostra que a responsabilidade da promoção e preservação do meio ambiente é um papel do poder público municipal e órgãos dependentes do mesmo e não da comunidade, Ver Figura 09.

Questionados se "Já fez ou costuma fazer algo para promoção da qualidade ambiental"?
Dos entrevistados, $88 \%$ responderam que não e, apenas, $12 \%$ afirmaram que sim. Foram apresentadas muitas dúvidas dos questionários, o que nos permite concluir que a sensibilização e a educação ambiental precisam ser bem mais trabalhadas entre a população para uma melhor avaliação crítica. Veja na figura10.

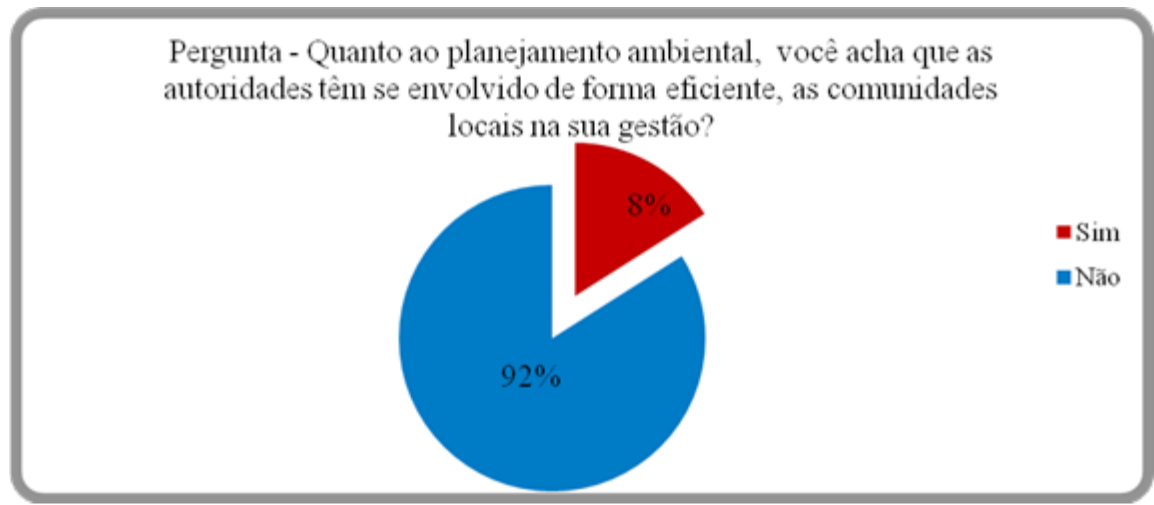

Figura 7. Gráfico de envolvimento da comunidade (\%).

Elaboração: Autores, 2018.

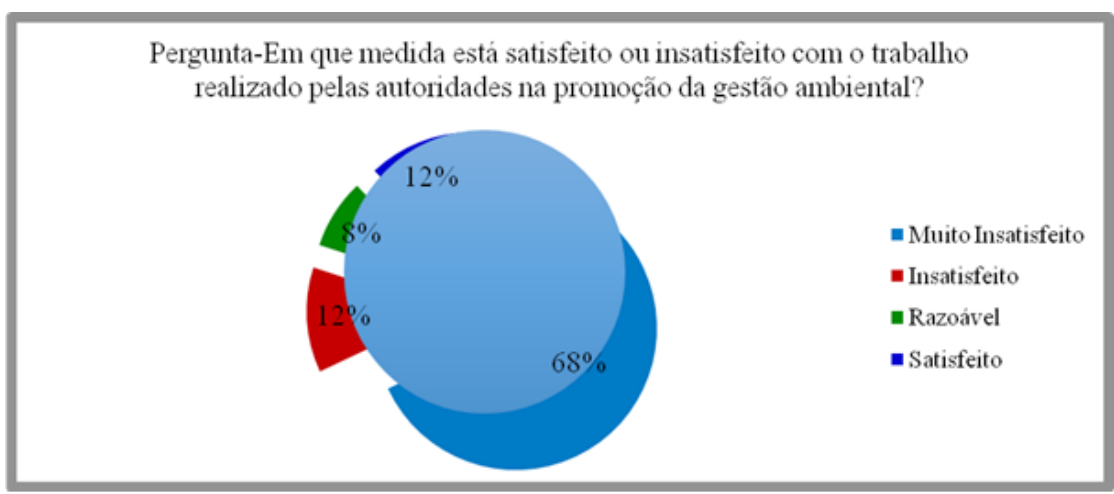

Figura 8 Gráfico com nível de satisfação na gestão (\%).

Elaboração: Autores, 2018.

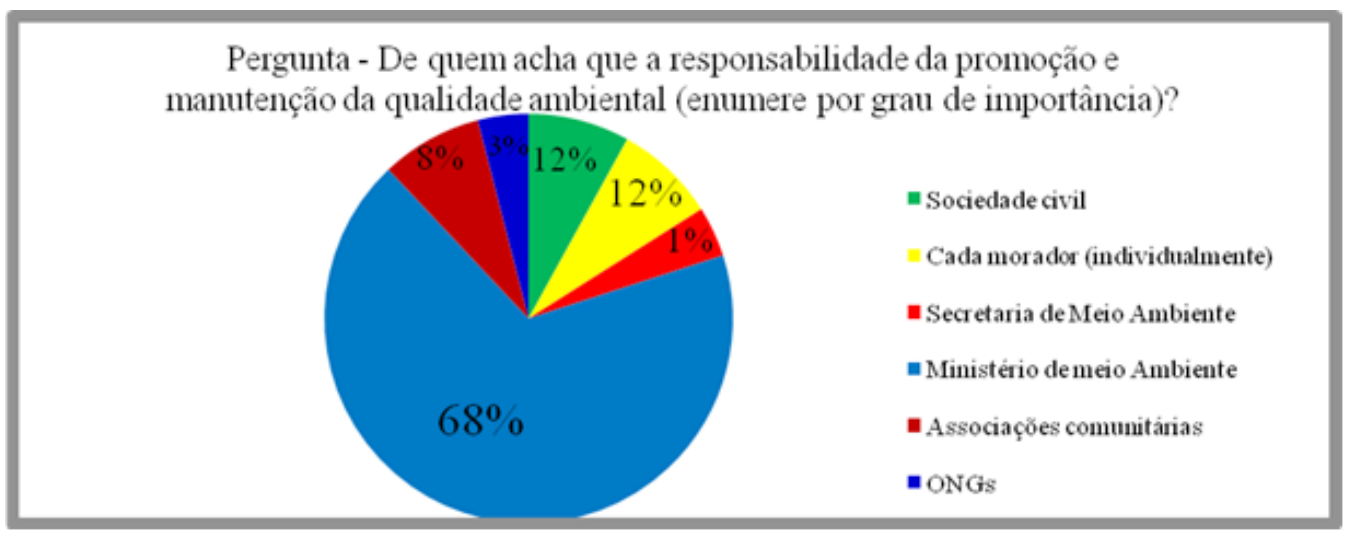

Figura 9. Gráfico de nivel de responsabilidade na qualidade ambiental (\%)

Elaboração: Autores, 2018. 
39 - Já fez ou costuma fazer algo para promoção da qualidade ambiental no seu municipio?

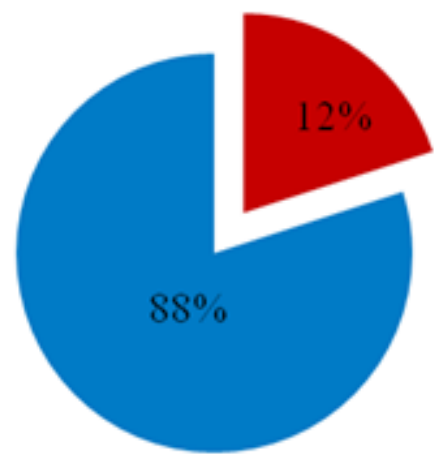

$\mathbf{n} \operatorname{sim}$

n Nă

Figura 10. Gráfico sobre promoção de qualidade ambiental (\%)

Elaboração: Autores, 2018.

A partir dos resultados da análise das respostas verificou-se a necessidade de trabalhar de forma diferenciada as questões ambientais, havendo uma grande necessidade de atenção do poder púbico para uma melhor gestão ambiental. A busca permanente da qualidade ambiental é, portanto, um processo de aprimoramento constante do sistema de gestãoambiental. A gestão ambiental não é obrigação somente dos governantes, mas também para a população em geral, o povo necessita de reeducação e cultura da importância deste assunto. Práticas simples como redução da exploração dos recursos naturais podem ser um bom começo.

O processo de gestão ambiental deve abranger uma nova cultura, uma mudança de consciência que nos leve a pensar e adotar novas formas de pensar no futuro. Os recursos naturais dependem de práticas responsáveis que devem ser geridas por uma ação coletiva das instituições, dos governos e da sociedade como um todo.

O desenvolvimento sustentável é um importante conceito de crescimento, presente no debate político internacional em especial quando se trata de questões referentes à qualidade ambiental e à distribuição global de uso de recursos.

\section{CONCLUSÃO}

Conclui-se que houve um grande avanço na gestão ambiental de Guiné-Bissau ao se instituir as áreas protegidas no município de Cacheu, além das grandes porções territoriais convertidas em áreas de preservação. Nesse território tem sido criado esforços estratégicos para a proteção de espécies, conservação de ecossistemas e a salvaguarda de populações tradicionais, buscando-se o bloqueio de atividades ilegais, promovendo o ordenamento territorial e desenvolvimento de atividades florestais sustentáveis. O grande desafio no momento é investir na efetiva implementação e fiscalização do Parque Natural dos Tarrafes do rio Cacheu-PNTC, e seu entorno como áreas protegidas. É preciso aumentar o número de planos de manejo a serem concluídos, a plena funcionalidadedoconselho gestores formados, bem como reforçar e qualificar o escasso quadro de funcionários lotados no parque.

O PNTC não está fora dos quadros das ameaças ambientais como os desmatamentos, as práticas de mineração, a exploração de madeireira e a tentativa de desafetação de algumas áreassão exemplos de impactos diretos sobre o Parque. Outros fatores, como 
a caça, a pesca, a agropecuária e os potenciais impactos indiretos gerados por projetos de infraestrutura e planos de construção de usinas hidrelétricas não foram abordados, mas, também, constituem sérias ameaças sobre essa localidade, indicando que a pressão sobre as áreas protegidas é maior do que a considerada na presente pesquisa.

Para garantir a integridade do PNTC, é necessário coibir usos e ocupações irregulares e o desmatamento, por meio da fiscalização local e monitoramento remoto, garantindo às populações locais seus direitos. Os órgãos ambientais (Nacional) e o Ministério Público podem contribuir com a fiscalização e o monitoramento a partir do investimento em novos recursos tecnológicos para aumentar a eficiência e transparência de suas ações, aliado a um programa de auditoria, capacitação e treinamento dos seus quadros de funcionários.

A escassez de recursos humanos e a insuficiência de recursos financeiros serão os grandes desafios dos próximos anos para a consolidação do PNTC. A fonte de financiamento do parque deve ser ampliada e os mecanismos de transferência de recursos devem ser transparentes, garantindo a alocação coerente do que é arrecadado, não apenas aos órgãos gestores de Instituto da Biodiversidade e das Áreas Protegidas (IBAP), mas também de forma a fortalecer iniciativas sustentáveis e cadeias produtivas que envolvam saberes tradicionais das comunidades locais. Outras fontes de financiamento, como União Internacional para a Conservação da Natureza e Recursos Naturais (UICN), e as outras iniciativas de cooperação internacional, são instrumentos decisivos para assegurar o futuro do parque como instrumentos de conservação da floresta do município de Cacheu.

As demais formações vegetais do município de Cacheu, como o manguezal, tem sido alvo de grande devastação nas últimas décadas pela ação antropogênica. Essa interferência do ser humano está vinculada ao processo de exploração de árvores arbustos existentes nesse domínio para a produção de lenha, carvão, defumagem dos peixes, vedação de casas, objetivando aproveitar essas áreas economicamente para construções dos edificios (especulação imobiliária).

Perante os obstáculos enfrentados pela população local, a exploração das florestas está sendo um dos principais caminhos para a resolução dos problemas, deste modo as orientações legais são ignoradas em função da permanente busca pela sobrevivência, tendo em conta que o Estado não demonstra ser capaz de reverter à situação de pobreza vivida pela população local ao longo do tempo. A biodiversidade dos manguezais se traduz em significativa fonte de alimentos para as populações humanas. Nesses ecossistemas se alimentam e se reproduzem mamíferos, aves, peixes, moluscos, crustáceos e entre outras espécies, algumas entendidas como recursos pesqueiros indispensáveis à subsistência tradicional das populações das zonas costeiras. Entre essas espécies destacam-se: os moluscos, crustáceos e peixes.

As destruições dos manguezais geram prejuízos ambientais, econômicos e culturais, uma vez que parte da fauna natural é fonte de renda, em especial na região costeira de Cacheu, onde o consumo de peixes faz parte da economia local, devido ao seu alto consumo. Por esses e outros motivos, a conservação desse ambiente é fundamental para manter o equilíbrio ambiental e conservar a fonte de renda a milhões de pescadores na Guiné-Bissau, que dependem desse habitat para seu sustento.

A não adequada conservação dos manguezais pode trazer graves consequências para a sobrevivência da fauna marinha e comprometer o ecossistema marinho oceânicos. Esses seres vivos fazem parte da alimentação de outras centenas de espécies de animais marinhos, que vivem nas águas mais profundas em alto-mar. 


\section{REFERÊNCIAS}

AJONINA, G. N.; KAIRO, J. G. Panorama sobre o estado atual e conservação dos manguezais na África. Revista Word press, ago. 2008. Disponível em: https:/ / wrmbulletin.w2. Acesso em: 10 dez. 2016.

ALVES, R.; NISHIDA, A. A ecdise do caranguejouça: ucidescordatus (Crustácea, Decapoda, Brachyura) na visão das caranguejeiras. Interciencia, Caracas, n.3, p.12, 2002.

ARASSI, M. TAVARES. Relatório sócio-económico do Parque Natural dos Tarrafes do Rio Cacheu, 1994.

BIAI, J. C. M. Análise das alterações das manchas de coberto vegetal nos Parques de Cacheu e Orango/Guiné-Biassau. Lisboa: Centro Nacional de Informação Geográfica, 2000.

CARVALHO, E.; ZAGAGLIA, E. Avaliação de áreas de mangues e apicuns, nos anos de 1998 e 2004, localizadas na ilha Santa Catarina. In: SIMPÓSIO BRASILEIRO DE SENSORIAMENTO REMOTO, 9., 2007, Florianópolis. Anais... Florianópolis: 2007.

ELLISON, A. M. Managing mangroves with benthic biodiversity in mind: moving beyond roving banitry. JournalSeaResearch, v. 59, 2008, p. 2-15.

FAO - A conservação dos recursos naturais: estimulando o desenvolvimento da pesca, da piscicultura, a proteção dos ecossistemas florestais e as fontes de energia, 2007.

FATOYINBO, T. E.; SIMARD, M. Height and biomass of mangroves in Africa from ICES at/GLAS and SRTM. International Journal of Remote Sensing, v. 34, n. 2, p. 668-681, 2013.
GANEM, R. S.; DRUMMOND, J. A. Biologia da conservação: as bases científicas da proteção da biodiversidade. In: GANEM, R. S. (Org). Conservação da biodiversidade: legislação e políticas públicas. Brasília: Edições Câmara, 2010.

GUINÉ-BISSAU. Lei das Áreas Protegidas. Decreto Lei A-5/11. Boletim Oficial 22, República da Guiné-Bissau. Bissau, 2011.

IBAP-INSTITUTO DE BIODIVERSIDADE E DAS ÁREAS PROTEGIDAS. Plano de gestão Parque Natural dos Tarrafes do Rio Cacheu - PNTC. Bissau, 2008.

IBAP-INSTITUTO DE BIODIVERSIDADE E DAS ÁREAS PROTEGIDAS. Estratégia nacional para as áreas protegidas e a conservação da biodiversidade na Guiné-Bissau 2014 - 2020, Bissau, 2014.

IBAP-INSTITUTO DE BIODIVERSIDADE E DAS ÁREAS PROTEGIDAS. Estratégia nacional para as áreas protegidas e a conservação da biodiversidade na Guiné-Bissau. Bissau: Draft, 2013.

INEC-INSTITUTO NACIONAL DE ESTATÍSTICA E CENSOS DA GUINÉ-BISSAU. Censo Demográfico-2009. Bissau, 2009.

LANNA, P. C. Novas formas de gestão dos manguezais brasileiros: a baía de Paranaguá como o estudo de caso. Desenvolvimento e Meio Ambiente: teoria e metodologia em meio ambiente e desenvolvimento, Curitiba, n. 10, p. 169-174, jul. 2004.

NASCIMENTO, I. A. Manguezal e carcinicultura: o conflito da compatibilidade. Dialogo \& Ciência - Revista da Rede de Ensino FTC, Salvador, ano 5, n. 10,p. 2, maio. 2007.

PACHECO. Análise geocológica direcionada ao planejamento gestão ambiental da 
Província de Sofala-Moçambique. 2014. $174 \mathrm{f}$. Tese (Doutorado em Desenvolvimento e Meio Ambiente)-Universidade Federal do Ceará, Fortaleza, 2014.

PHILIPPI JR., A. P.; ROMÉRIO, M. A.; BRUNA, G. C. Curso de gestão ambiental. 2. ed. São Paulo: Atlas, 2004.

QUEIROZ, L. S.; MEIRELES, A. J. A.; HERAS, S. R. Serviços Ecossistêmicos costeiros e comunidades tradicionais. Revista da ANPEGE, Dourados, v.8, n.10, p. 145-159, 2012.

QUINTAS, J. S. Educação no processo de gestão ambiental: uma proposta de Educação Ambiental transformadora e emancipatória. In: BRASIL. Ministério do Meio Ambiente. Identidade da educação ambiental brasileira. Brasília: Ministério de Meio Ambiente, 2004.

RODRIGUES, J. M. M.; SILVA, E. V da; CAVALCANTI, A. P. B. Geoecologia das paisagens: uma visão geossistêmica da análise ambiental. 2. ed. Fortaleza: Edições UFC, 2007.

SANTOS, R. R. Planejamento ambiental: teoria e prática. São Paulo: Oficinas de Textos, 2004.

SCHAEFFER-NOVELLI Y. Manguezal, marisma e apicum (Diagnóstico Preliminar). In: Fundação BIO - RIO; Secretaria de Estado de Ciência, Tecnologia e Meio Ambiente do Rio Grande do Norte-DEMA;Sociedade Nordestina de Ecologia - SNE (el al). (Org.). MMA- Ministério do Meio Ambiente 2002. Avaliações e ações prioritárias para conservação da biodiversidade das Zonas Costeiras e Marinhas. Brasilia: MMA/ SBF, 2002. Disponível em:<http://www.anp. gov.br/ibamaperfuraçao/refere/manguezalmarisma-apicum.pdf>acesso em set. de 2016.

SEIFFERT, M. E. B. Gestão ambiental: instrumentos, esferas de ação e educação Ambiental. São Paulo: [s.n.], 2014.
SEXTON, J. O.; Noojipady, P.; Xiao-peng, S.; Feng, M, Dan-xia, S.; Do-Hyunk, A. A.; Huang, C.; Channan, S.; Pimm, S. L. Townshend, JR. Nature Clim. Change, Vol. advance online publication.2015.

SILVA, E.V. Modelo de aprovechamiento y preservación de losmangles de Marisco y Barro Preto, Aquiraz-Ceará. Dissertação de Mestrado, IAMZ, Zaragoza, 1987.

SILVA, E. L. P.; WANDERLEY, M. B.; CONSERVA, M. S. Proteção social e território na pesca artesanal do litoral paraibano. Serv. Soc. Soc., São Paulo, SP, v. 1, n. 117, p. 169-188, 2014. Disponível em: <http://www.scielo.br/pdf/ sssoc/n117/10.pdf>. Acessoem: 10 mio. 2017.

SPALDINGM. F.; BLASCO, F; FIELD, C. Worldmangroveatlas. Okinawa: The InternacionalSocitety for Mangrove Ecosystems, 1999.

THIERS, P. R. L.; MEIRELES, A. J. A.; SANTOS, J. O. Manguezais na costa oeste cearense: preservação permeada de meias verdades. Fortaleza: Imprensa Universitária da Universidade Federal do Ceará, 2016.

VANNUCCI, M. Os manguezais e nós: uma síntese de percepções. 2. ed. São Paulo: Ed. USP, 2003. 